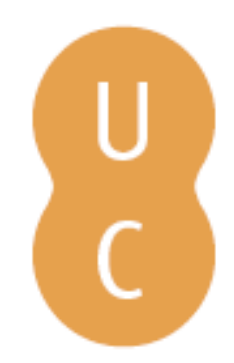



\section{Miguel Bombarda: reorganizador e gestor de Rilhafoles}

Autor(es): $\quad$ Oliveira, J. F. Reis de

Publicado por: Imprensa da Universidade de Coimbra

URL

persistente: URI:http://hdl.handle.net/10316.2/32330

DOI: $\quad$ DOI:http://dx.doi.org/10.14195/978-989-26-0362-9_15

Accessed : $\quad$ 26-Apr-2023 15:22:15

A navegação consulta e descarregamento dos títulos inseridos nas Bibliotecas Digitais UC Digitalis, UC Pombalina e UC Impactum, pressupõem a aceitação plena e sem reservas dos Termos e Condições de Uso destas Bibliotecas Digitais, disponíveis em https://digitalis.uc.pt/pt-pt/termos.

Conforme exposto nos referidos Termos e Condições de Uso, o descarregamento de títulos de acesso restrito requer uma licença válida de autorização devendo o utilizador aceder ao(s) documento(s) a partir de um endereço de IP da instituição detentora da supramencionada licença.

Ao utilizador é apenas permitido o descarregamento para uso pessoal, pelo que o emprego do(s) título(s) descarregado(s) para outro fim, designadamente comercial, carece de autorização do respetivo autor ou editor da obra.

Na medida em que todas as obras da UC Digitalis se encontram protegidas pelo Código do Direito de Autor e Direitos Conexos e demais legislação aplicável, toda a cópia, parcial ou total, deste documento, nos casos em que é legalmente admitida, deverá conter ou fazer-se acompanhar por este aviso. 
Ana Leonar Pereira Jםão Rui Pita [ Coordenaçä̃ ]

\section{Miguel Bomberda e as singularidades de uma época}

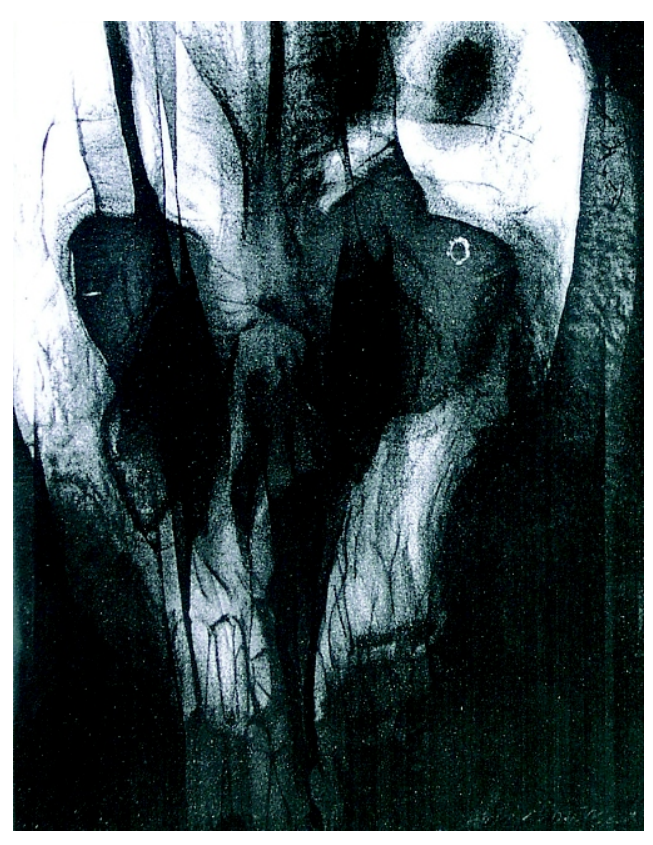


(Página deixada propositadamente em branco) 
Ana Leonor Pereira

João Rui Pita

(Coordenação)

\title{
FOLHA DE ROSTO
}

\author{
Miguel Bombarda (1851-1910)
}

a as singularidades de uma época 


\section{Coordenação Científica da Colecção Ciências e Culturas}

João Rui Pita e Ana Leonor Pereira

Os originais enviados são sujeitos a apreciação científica por referees

\section{Coordenação Editorial}

Maria João Padez Ferreira de Castro

\section{Edição}

Imprensa da Universidade de Coimbra

Email: impresauc@ci.uc.pt

URL: http://www.imp.uc.pt • Normas de publicação de colecções

Design

António Barros

Pré-Impressão

António Resende

Imprensa da Universidade de Coimbra

Capa

António Dantas. Sem título, 2002. Col. António Barros. Coimbra

Impressão e Acabamento

SerSilito • Maia

\section{ISBN}

978-989-8074-11-9

\section{Depósito Legal}

Obra publicada com a colaboração de:
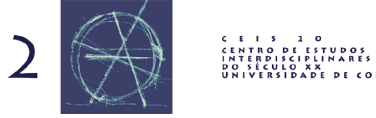

Obra publicada com o apoio de:

FCT Fundação para a Ciência e a Tecnologia

MINISTÉRIO DA CIÊNCIA, TECNOLOGIA E ENSINO SUPERIOR Portugal

Programa Operacional Ciência, Tecnologia, Inovação do Quadro Comunitário de Apoio III

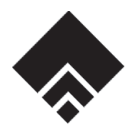

Fundaçāo Eng. António de Almeida

(C) Agosto 2006, Imprensa da Universidade de Coimbra 


\section{J. F. Reis de Oliveira}

Hospital de Santa Maria, Lisboa, Portugal

\section{MIGUEL BOMBARDA: \\ REORGANIZADOR E GESTOR DE RILHAFOLES}

Quando em 1848 o Duque de Saldanha propõe a transferência imediata dos alienados a viver em condições sub-humanas no Real Hospital de S. José para Rilhafolles, inicia-se, sem dúvida, em Portugal um novo capitulo na assistência aos doentes mentais. Começa então a história do Hospital de Rilhafolles, actual HMB.

Dois anos volvidos, em 1851, Rilhafolles foi dotado de um Regulamento, publicado a 7 de Abril, que irá reger a vida da instituição por largas décadas.

Ainda que fosse reconhecido que o Hospital de Rilhafolles reunia na sua organização e administração interna as necessárias condiçōes de vida própria e independente eram aduzidas razões económicas como justificação da sua dependência em relação a S. José.

O orçamento de receita e despesa figurava no orçamento geral de S. José e anexos. A nomeação de empregados subalternos, o pagamento dos vencimentos, o fornecimento dos medicamentos e um largo etc. eram assegurados pelo Hospital de S. José.

Apesar da dinâmica introduzida em Rilhafolles por Miguel Bombarda e da sua insistência, sempre justificada, para assegurar a autonomia do Hospital, tal só virá a ocorrer em 1945 (Lei 2006). Isto é, trinta e cinco anos após a sua morte.

A última década do séc. XIX veio encontrar Rilhafolles num caos indescritível pouco ou nada se sabendo do período que medeia entre 1872 e a tomada de posse de Miguel Bombarda em 2 de Julho de 1892. Para a direcção do Hospital Rilhafolles, Bombarda fora indicado pelo Conselheiro Dias Ferreira, então presidente do Conselho de Ministros. Era à época médico em S. José onde entre outras actividades respondia pela Consulta Externa de Doenças Nervosas e Mentaes, denominada Clínica do Dr. Miguel Bombarda.

A imprensa da época referia-se a Rilhafolles como sendo um antro em que as condiçôes de vida e assistência eram péssimas e a mortalidade elevada.

No entanto nem sempre fora assim já que é justo salientar que Rilhafolles vivera um efémero período de bem estar com Guilherme Abranches em 1866. Este propusera melhoramentos e reformas que passavam pela necessidade de mais dois hospitais e asilos no país, de um novo hospital-modelo nas terras de Rilhafolles e na sua desacumulação entregando às famílias os alienados incuráveis. 
Mas o que aqui nos traz é a obra de Miguel Bombarda enquanto gestor e reformador de Rilhafolles. A par da reorganização e melhoria das condições de higiene e de assistência aos doentes, Miguel Bombarda pugnou pela disciplina dos métodos coercivos usados e pela reforma das mentalidade de muitos funcionários.

Miguel Bombarda estava empenhado em acabar com a reputação horrorosa da instituição e como o próprio escreveu na introdução de relatório de 1892/93, «levantar Rilhafolles a uma altura não sonhada anteriormente».

Para Rilhafolles transferiu as suas ideias influenciado pelo que no domínio da Psiquiatria se fazia na Europa, particularmente em Alt-Scherbitz, na Alemanha, estimulado pela obra do Dr. Albrecht Paetz.

É particularmente interessante fazer a comparação entre dois relatórios que Bombarda redigiu relativos aos anos de 1892/93 e 1896/97. O primeiro é o de análise da situação encontrada e dos projectos e remodelaçóes a que submeteu todos os serviços logo que passaram à suas mãos. Propunha-se levar a cabo um plano metódico a que chamou "a reorganização sanitária, nosocomial, disciplinar, policial e administrativa de Rilhafolles» já que o velho convento se encontrava num estado de indiscritível ruína. O outro relatório é o dos objectivos atingidos e da profunda transformação operada em Rilhafolles não deixando de enaltecer o empenho que o Governo demonstrara pela instituição e que possibilitara as grandes transformações e melhorias. Com orgulho afirmava que das ruínas em que encontrara Rilhafolles não havia memória nem fotográfica e que apesar da singeleza, mesmo pobreza do aspecto do Hospital este não envergonhava. "Via-se que estava ali um estabelecimento do Estado», concluía.

Este relatório relativo ao ano de 1896/97 mereceu louvor real publicado no Diário do Governo de 21 de Fevereiro de 1898 pela proficiência com que estava redigido e pela grande utilidade dos esclarecimento prestados sobre todos os assuntos relativos à vida clínica e económica de Rilhafolles.

Durante os 18 anos em que exerceu a Direcção de Rilhafolles, Miguel Bombarda sempre redigiu os seus relatórios. Alguns, muito detalhados, outros, sobretudo a partir de 1900 extraordinariamente sucintos, resumidos a dados estatísticos. O escrito e o omitido dão-nos a dimensão interventiva em Rilhafolles.

Apreendemos as realizaçōes e compreendemos as frustrações. Pressentimos também que a política o absorvia e entusiasmava.

Dado o conhecimento que Miguel Bombarda tinha do Hospital de Rilhafolles e que vinha dos seus tempos de estudante estava desde logo apto a introduzir as reformas que se afiguravam mais urgentes. Aliás o seu interesse pela Psiquiatria já se deixara antever aquando da licenciatura em Medicina pela Escola Médico-Cirurgica de Lisboa com a defesa da tese em 1877 sobre «delírio das perseguiçôes».

O relatório de 1892/93 dividia-se em três partes (serviço médico; serviço administrativo, reformas e melhoramentos), precedido de introdução e acompanhamento de gráficos, modelos de impressos mapas e desenhos e planta e concluindo com quatro propostas:

1. Grandes melhoramentos

2. Construçôes a empreender

3. Reformas do regulamento - Pessoal

4. Outras modificações do Regulamento 
Desde logo a primeira tomada de posição consistiu em dar ar puro aos doentes, cerca de 500, dos quais 330 se acumulavam no velho edifício. Nas barracas construídas na cerca estavam instaladas 140 camas.

Os cuidados hoteleiros mereceram de Miguel Bombarda a melhor atenção. O hospital foi dotado de móveis e utensílios funcionais - bancos, mesas, caixas de retrete, lavatório, pratos de folha, colheres de pau, tigelas e roupas brancas para as camas. Reformulou as dietas e melhorou as condições higiénicas. Estabeleceu serviços regulares de banhos de limpeza e introduziu o calçado de fechadura. Criou oficinas e incentivou o trabalho agrícola para aproveitar as aptidóes dos doentes e obter receitas para Rilhafolles. A ocupação dos doentes constituía factor de estabilidade emocional e simultaneamente era encarada como redutor de pessoal necessário. O quadro de pessoal de Rilhafolles era escassíssimo e permaneceu praticamente inalterável durante a vigência da direcção de Bombarda, com todos os inconvenientes daí decorrentes. Dois médicos para 530 doentes, mais um cirurgião.

Ora o número de doentes continuou a aumentar atingindo em 1898, 700 doentes.

Os pavilhões em duplo E, cuja construção se arrastava há oito anos, ficaram concluídos em 1894. Beneficiaram de imediato toda a população masculina do Hospital permitindo a evacuação do hospício das Recolhidas.

As condições higiénicas da instituição melhoraram substancialmente diminuindo a mortalidade como se comprova pelo quadro seguinte:

$\begin{array}{ll}1893 / 94 & 26,4 \% \\ 1894 / 95 & 18,0 \% \\ 1895 / 96 & 15,4 \%\end{array}$

A plena utilização dos novos pavilhões e a mudança das doentes das enfermarias na cave onde tinham sido alojadas durante o período de obras, esteve na origem de tal facto. Entre 1902 e 1909 a taxa de mortalidade voltou de novo a ser factor desestabilizador em Rilhafolles atingindo os $24,2 \%$ em 1902/03. Como causa próxima a epidemia de enterite nesse ano. Enterite que se manteve actuante nos anos subsequentes.

Os doentes foram divididos por categorias.

Enquanto não se ultrapassaram as dificuldades em estabelecer a iluminação pela electricidade em todo o hospital o número de enfermarias que passou a beneficiar de iluminação pelo gaz foi aumentado.

Com o decorrer do tempo foi restaurado e ampliado o balneário, construída uma cozinha moderna, a casa mortuária, o laboratório, o largo salão em arcos que veio substituir o refeitório que se situava logo à entrada do hospital, a escadaria principal do edifício, melhorada a canalização da distribuição da água, construído um reservatório para a água e edificado em 1896 o pavilhão de segurança.

De todas as construções da iniciativa de Bombarda a mais importante foi sem dúvida o edifício onde se instalaram as ex- $5^{a}$ e $6^{a}$ enfermarias de homens.

Nessa construção, concluída no período de 1900/01, Bombarda procurou aplicar conhecimentos adquiridos na viagem de estudo que realizou em 1898 por alguns países da Europa visitando unidades psiquiátricas em Paris, Würzburgo, Leipzig, Viena e Lucerna e de que se fez eco na «Medicina Contemporânea». 
O tipo de colónia agrícola que observara em Alt-Scherbitz na Alemanha era, na sua opinião, "o mais formoso modelo» mas não poderia ser transposto para Rilhafolles por escassez de área. Alt-Scherbitz, uma propriedade rústica no meio da qual se inseriam os pavilhôes permitia a liberdade aos doentes de se ocuparem de actividades diversas, na lavoura ou em oficinas.

Desde o inicio da sua direcção que Bombarda demonstrou interesse no alargamento da área da cerca do hospital. Na sua envolvente ficava a Quinta do Borba, Conde de Redondo. A justificação para a aquisição de alguns hectares ou de toda a quinta, o que considerava ser um bom negócio, decorria do facto que permitiria não só edificar como aumentar a zona de cultura e com isso incrementar o trabalho da quinta criando uma colónia agrícola à semelhança do que existia em Inglaterra e na Alemanha. O modelo inspirador era o delineado pelo Dr. Paetz em 1876 o dos asilos-colónias em que se aplicava o sistema de open-door, aliado a uma vigilância constante e um tratamento sério. Nada de construções uniformizadas, muros altos e grades nas janelas com os doentes devidamente classificados em pavilhôes que continham entre 25 a 40 doentes. Os terrenos do Borba também iriam permitir construir pavilhões para as mulheres que continuavam muito fechadas.

Quando em 1898 a população do hospital já atingia os 700 doentes e o quadro do pessoal e salários continuavam iguais aos de 1848, Bombarda ainda insiste nos terrenos do Borba que possibilitariam, ainda que apenas num esboço, algo de semelhante a Alt-Scherbitz. Esta esperança foi definitivamente perdida quando em 1899 nos terrenos em questão começou a ganhar forma um bairro. A solução de recurso foi o edifício da cerca a que já nos referimos concluído em 1901 e que acolheu cerca de 200 doentes.

Miguel Bombarda pugnou pela autonomia do Hospital Rilhafolles na medida em que tinha receitas importantes e era no conjunto dos anexos do Hospital de S. José o hospital que menos encargos acarretava à Administração Geral. Isto porque as despesas em medicamentos eram menores e em contrapartida Rilhafolles contribuía com os rendimentos da Quinta, dos banhos a pessoas estranhas ao estabelecimento, dos Pensionistas, das oficinas (de costura, engomagem, sapataria, colchoaria), contando ainda com receitas várias (fábrica da igreja, ossos, cinza, venda de coletes de força). Compulsando a "Conta de Gerência Financeira e estatística económica e de população relativas ao ano de 1891/92" Miguel Bombarda concluiu que o doente internado em Rilhafolles despendia 53\% do que despendia a média dos internados nos outros hospitais do grupo. O custo médio diário do tratamento era 649,9 enquanto em Rilhafolles apenas se elevava a um máximo de 242,2. Assim, "os rendimentos próprios de Rilhafolles constituíam fonte de receita para os outros hospitais».

Bombarda dinamizou todos os serviços administrativos de Rilhafolles à época totalmente desprezados. Foram preparados livros e cadernos clínicos. Determinou a escrituração de livros de receitas e despesas com vista à elaboração de propostas de orçamento. Como gestor sempre foi sua preocupação o equilibro das receitas e despesas de Rilhafolles.

De acordo com o Regulamento de 1851 o Hospital de alienados em Rilhafolles dividia-se em serviços clínicos, administrativo e religioso. Ao médico director competia a direcção geral do Hospital assim como a coordenação do todo o serviço administrativo interno, e o regime sanitário e policial dos alienados (art. $\left.{ }^{\circ} 13^{\circ}\right)$. 
No Director recaiam simultaneamente as funçôes de médico e administrador. $\mathrm{O}$ art. ${ }^{\circ} 10^{\circ}$ do regulamento determinava a apresentação anual para aprovação da autoridade superior do orçamento geral da despesa do hospital bem como quaisquer orçamentos adicionais. Os antecessores de Miguel Bombarda não lhe tinham deixado qualquer base de trabalho.

Inteiramente desconhecedor das exigências administrativas do hospital, Bombarda procurou saber as necessidades e organizar os registos de forma a que todas as requisições que até então eram feitas passassem a ser acompanhadas, uma vez satisfeitas, das respectivas importâncias. Na secretaria do hospital começaram a ser escriturados os livros de receita e despesa que permitissem facultar dados para a elaboração dos futuros orçamentos.

Bombarda concentrou no fiel da fazenda (também chefe dos enfermeiros) todo o serviço de gerência económica que superintendia e criou um embrionário serviço de aprovisionamento com os seus armazéns. As requisições passaram a ser centralizadas e escrituradas. Simultaneamente Miguel Bombarda confiou ao escriturário do hospital o serviço de balanço e a quem competia a verificação ordinária ou extraordinária dos inventários sob a responsabilidade dos diversos chefes de serviço hospitalar. O estatuto deste funcionário foi reforçado tornando-se num poderoso auxiliar do director já que Bombarda não podia dedicar todo o seu tempo às absorventes minúcias administrativas.

\section{Alguns indicadores}

A análise de alguns indicadores estatísticos é por si só elucidativa do intenso movimento que no Hospital de Rilhafolles se registou com o advento da administração de Bombarda.

As admissões entre 1892 e 1909 não cessaram de aumentar. A população internada fixa em Rilhafolles foi atingindo, consequentemente, valores cada vez mais altos.

De 536 residentes em 1892/93, atingiu-se o número de 738 em 1908/09. A média diária de existência cifrava-se em 695,5 doentes. A acumulação era reflexo directo da carga asilar. As admissōes de carácter urgente e as readmissōes não apresentaram valores significativos, no período considerado. A abertura do Hospital Conde de Ferreira em 1883 não parece ter influído na afluência a Rilhafolles.

A curabilidade denotava a melhoria substancial verificada no tratamento e cuidados hoteleiros sendo da ordem dos 36,28\% em 1895/96 e de 42,2\% em 1901/02.

O número de banhos (tratamento; limpeza) administrados aos doentes, que em

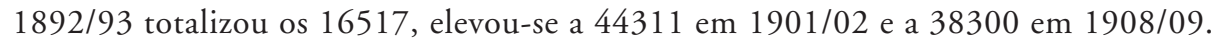
Também o consumo de água foi substancial, particularmente entre 1895 e 1898, coincidindo com o período de maior actividade na Quinta.

$\mathrm{Da}$ análise de outros indicadores infere-se que no período compreendido entre 1892 e 1909 na demanda a Rilhafolles preponderaram os naturais do Distrito de Lisboa e muito em particular os residentes no distrito da capital, numa percentagem superior a $50 \%$, comparativamente com o resto do país. O número de residentes no interior do país, nas ilhas e nas colónias e que eram enviados para Rilhafolles era pouco significativo. A atracção geográfica de Rilhafolles podia ser encarada mais 
num contexto distrital que nacional. O grupo etário mais frequente entre os doentes mentais no período em apreciação citava-se na faixa compreendida entre os 21 e os 35 anos de idade, predominantemente solteiros e de filiação legítima. Os artífices e os trabalhadores rurais detinham forte incidência constituindo os contigentes mais densos de Rilhafolles os doentes cuja profissão era ignorada ou não tinham profissão. A situação social dos doentes contemplava duas categorias-pensionistas e indigentes subdividindo-se a primeira em quatro classes. Os pensionistas constituiram sempre uma percentagem superior a $11 \%$ da população total de Rilhafolles, chegando a atingir 20 e $23 \%$ em 1893/94 e 1907/08, respectivamente.

As mensalidades estavam, em 1892, francamente desactualizadas. Assim, sob proposta de Miguel Bombarda o governo publicou o Decreto de 8 de Novembro de 1892 que veio alterar os preços pagos pelos pensionistas e que se mantinham inalteráveis desde 1859.

Também o ensino da Psiquiatria mereceu de Bombarda a melhor atenção iniciando em 1896 em Rilhafolles o seu ensino livre. A formação de médicos alienistas já havia sido objecto de reflexão no relatório de 1892/93 aquando das linhas programáticas da sua actuação. Oficialmente só foi introduzido nos estudos médicos em 1911.

Também o trabalho de investigação clínica e laboratorial o apaixonou. As suas contribuiçôes apensas aos relatórios ou editadas em "A Medicina Contemporânea» foram do maior interesse.

Compreendemos assim que para Miguel Bombarda os níveis de assistência, do ensino e da investigação se entrozavam no todo geral da organização do hospital.

Em conclusão Miguel Bombarda foi gestor e reorganizador de Rilhafolles, sem dúvida. Brilhante também. E com obra feita.

Resumo - Nomeado director do Hospital de Rilhafolles em Julho de 1892, pelo Conselheiro Dias Ferreira, então presidente do Conselho de Ministros, Miguel Bombarda encontrou um hospital que tinha atingido elevado grau de degradação. Impunha-se assim a reorganização sanitária, nosocomial, disciplinar, policial e administrativa.

Bombarda transferiu para Rilhafolles os seus ideais, influenciado pelo que no domínio de Psiquiatria se fazia na Europa, empenhando todo o seu esforço, capacidade intelectual e organizativa para, como escreveu no seu primeiro relatório de 1892/1893, levantar Rilhafolles a uma altura não sonhada anteriormente.

O seu plano de acção foi brilhantemente detalhado nos primeiros relatórios de 1892/1893 e 1893/1894. Empreendeu a construção de novos pavilhōes, melhorou a higiene, as dietas, a terapêutica ocupacional. Preparou livros e cadernos clínicos. Pugnou pela disciplina dos métodos coercivos em uso. Dinamizou todos os Serviços Administrativos, à época totalmente desprezados. Determinou a escrituração de livros das receitas e despesas com vista à elaboração de propostas de orçamento.

Todos os relatórios, sobre o Serviço do Hospital, que entre 1892 e 1909 publicou, demonstram determinação, firmeza e o rigor do gestor que maneja com à vontade os indicadores estatísticos mas que não perdia de vista a dimensão humana.

Nestes relatórios apreendemos todas as grandes intervençôes realizadas em Rilhafolles a par de algumas frustraçôes. E compreendemos que para Miguel Bombarda os níveis da assistência, do ensino e da investigação se entrozavam num todo da organização geral de um hospital.

Miguel Bombarda foi gestor, sem dúvida. Brilhante, também. E com obra feita!

Abstract - When Miguel Bombarda was appointed as director of Rilhafolles Hospital by Counsellor Dias Ferreira (President of the Ministers' Counsel at the time) in 1892, he found a hospital that had reached a very serious point of degradation. Sanitary, nosocomial, disciplinary, police, and administrative reorganisation was urgent. 
In Rilhafolles, Bombarda put his ideals into practice, influenced by what was being done in Europe in the field of Psychiatry. He made use of all his efforts, and intellectual and organizative capacity to raise Rilhafolles to a level never imagined before, as he wrote in his first report concerning 1892/1893.

His action plan was brilliantly presented in the first reports of $1892 / 1893$ and $1893 / 1894$. He built new pavilions, improved hygiene, diets, and occupational therapy. He prepared clinical books, struggled for the discipline of coercive methods in use, animated all the Administrative services, totally disregarded at the time. He determined the book-keeping of incomes and expenses in order to draw up budget proposals.

All the reports about Hospital Service published between 1892 and 1909 showed the determination, firmness and rigour of the manager, who could perfectly manage the statistical indicators but never the human aspect.

Through these reports one becomes aware of the important interventions made in Rilhafolles as well as of some frustrations. We realise that to Miguel Bombarda the assistance, teaching, and research areas were all part of the general organization of a hospital.

Miguel Bombarda was undoubtedly a manager. A brilliant one. And he left work done too! 


\section{Colecção \\ Ciências e Culturas \\ Cuimbra 2006}

